\title{
Transplacental transmission of tick-borne Babesia microti in its natural host Peromyscus leucopus
}

\author{
Danielle M. Tufts ${ }^{*}$ and Maria A. Diuk-Wasser
}

\begin{abstract}
Background: Babesia microti is an emerging tick-borne pathogen and the causative agent of human babesiosis. Mathematical modeling of the reproductive rate of $B$. microti indicates that it cannot persist in nature by horizontal tick-host transmission alone. We hypothesized that transplacental transmission in the reservoir population contributes to B. microti persistence and emergence in North American rodent populations.

Methods: Peromyscus leucopus were collected from Connecticut and Block Island, Rhode Island and analyzed using a highly specific quantitative PCR (qPCR) assay for infection with $B$. microti.

Results: In April, 100\% ( $n=103$ ) of mice were infected with B. microti. Females exhibited significantly higher parasitemia than their offspring $(P<0.0001)$ and transplacental transmission was observed in $74.2 \%$ of embryos $(n=89)$. Transplacental transmission of $B$. microti is thus a viable and potentially important infectious pathway in naturally infected rodent species and should be considered in future theoretical and empirical studies.

Conclusions: To our knowledge, this study is the first to report transplacental transmission of B. microti occurring in its natural reservoir host, $P$. leucopus, in the United States and the only study that provides a quantitative estimate of parasitemia. This vector-independent pathway could contribute to the increased geographic range of $B$. microti or increase its abundance in endemic areas.
\end{abstract}

Keywords: Ixodes scapularis, Rodent, Babesiosis, Emerging disease, Congenital transmission

\section{Background}

Babesia microti (Apicoplexa: Sporozoea) is a zoonotic intraerythrocytic apicomplexan parasite and is responsible for almost all cases of human babesiosis in the United States [1]. Human babesiosis is an emerging tickborne disease that shares the same vector, the blacklegged tick (Ixodes scapularis), and dominant reservoir host, the white-footed mouse (Peromyscus leucopus), as the causative agent of Lyme disease, the spirochete Borrelia burgdorferi [2]. During the last 20 years, human babesiosis has spread in the United States $[3,4]$ following a similar trajectory to that of Lyme disease, although with a temporal lag [5-7]. Factors accounting for the delayed spread of babesiosis compared to Lyme disease include lower fitness in the enzootic cycle because of

\footnotetext{
* Correspondence: dt2503@columbia.edu

Ecology, Evolution, and Environmental Biology Department, Columbia University, New York, NY 10027, USA
}

lower transmission from infected host to tick and lower trans-stadial transmission, greater asymptomatic infection in humans, insufficient physician awareness, and underdiagnosis in non- or newly-endemic areas $[1,5,6]$.

An integrated measure of $B$. microti fitness (the basic reproductive number, $R_{0}$ ) was estimated to be lower than the threshold for pathogen persistence $\left(R_{0}<1\right)$ under ecological conditions identified in long-term field studies $[6,8]$ implying that emergence of this pathogen should be unlikely in nature. However, despite the low predicted $R_{0}$, B. microti has not only persisted in multiple locations with high infection prevalence in ticks regionally [5, 9-11], but it is also geographically expanding in the Northeast and upper Midwest regions of the USA [6]. This paradoxical finding suggests additional mechanism(s) enhancing $B$. microti transmission and persistence in the enzootic cycle may be occurring. Previous field studies reported higher average infection prevalences of B. burgdorferi (22.37\%) 
compared to B. microti $(9.53 \%)$ in nymphal I. scapularis ticks throughout the New England area [6]. However, very little is known about the B. microti infection status of $P$. leucopus in nature.

The aims of this research were to (i) determine if transplacental transmission of B. microti occurs in naturally infected, wild reservoir $P$. leucopus mice and (ii) quantify the level of transplacental transmission of host populations in B. microti-endemic coastal New England. As a comparison for early season infection prevalence we also screened for the presence of B. burgdorferi in the same host population; B. burgdorferi is not known to be transmitted transplacentally $[12,13]$.

\section{Methods}

\section{Study site and animals}

Adult Peromyscus leucopus were collected from two locations in Connecticut [Lake Gaillard (LG) $41^{\circ} 22^{\prime} 25.3^{\prime \prime} \mathrm{N}$, $72^{\circ} 46^{\prime} 43^{\prime \prime} \mathrm{W}$ and Old Lyme (OL) $41^{\circ} 22^{\prime} 21.5^{\prime \prime} \mathrm{N}, 72^{\circ} 20^{\prime} 37$. $6 " \mathrm{~W}]$ and two locations on Block Island, Rhode Island [North Island (NI) 41 $1^{\circ} 12^{\prime} 36.4^{\prime \prime} \mathrm{N}, \quad 71^{\circ} 34^{\prime} 18.8^{\prime \prime W}$ and Rodman's Hollow (RH) 41 $09^{\prime} 25.2^{\prime \prime N}, 71^{\circ} 35^{\prime} 22.9^{\prime \prime W] ~ f o r ~}$ two trapping sessions from April 26 - May 2 (hereafter referred to as April) and July 23-31, 2016. In each trapping session, animals were trapped for two consecutive nights using Sherman live traps $(7.62 \times 8.89 \times 22.86 \mathrm{~cm}$; H.B. Sherman Traps, Inc. Tallahassee, FL) baited with peanut butter, oats, and sunflower seeds. Traps were arranged in nine $200 \mathrm{~m}$ transects with one trap placed every $10 \mathrm{~m}$ for a total of 180 traps at each location, except for NI where $100 \mathrm{~m}$ transects were used for a total of 90 traps.

Animals were removed from traps, morphological characteristics (age, sex, weight, body measurements, etc.) were collected, and attached larval and nymphal ticks were counted and removed from the ears and body. All animals were euthanized with an overdose of isoflurane and necropsied immediately in the field. All organs and tissues were preserved in liquid nitrogen, blood samples were dried on Whatman FTA cards (Fisher Scientific, Pittsburg, PA, USA), and the carcasses were wrapped in Whirl-Pak bags (Whirl-Pak ${ }^{\oplus}$, Nasco, Fort Atkinson, WI, USA) and frozen in liquid nitrogen; embryos of pregnant females remained within the carcass. All samples were transferred to $-80{ }^{\circ} \mathrm{C}$ for long term storage upon return to the laboratory. All animal procedures were in accordance with guidelines approved by the Columbia University Institutional Animal Care and Use Committee (IACUC no. AC-AAAL3656).

\section{Embryo necropsy}

To ensure no cross contamination of maternal blood occurred during the necropsy of embryos from the female's body cavity, a new pair of autoclaved dissecting utensils were used for each adult female. Utensils were soaked in a $10 \%$ bleach solution and then in $70 \%$ ethanol for at least 2 min between sampling embryos from the same adult female. All embryos were removed from the body cavity of the female, washed with a saline solution, photographed, immediately cut into sections around each embryo, and then transferred to a separate sterile Petri dish. Embryos were found in various stages of development. Because the gestation time of $P$. leucopus is 22-28 days, embryos were separated into three developmental age categories (Week 1, Week 2, Week 3; Fig. 1) based on the size and the presence or absence of various developmental characteristics for each embryo (i.e. eye spot, placenta, limbs and tail, etc.). Week 1 embryos were very small with little to no distinguishing characteristics. Week 2 embryos were larger with a small placenta, could be removed from the uterus, and a distinctive eyespot was observed. Week 3 embryos were large with almost fully developed characteristics. A 25 mg sample of the following tissue types was collected: the uterine arteries and veins, the uterus surrounding each individual embryo, the placenta if present, and the embryonic sac surrounding each embryo if available. Utensils were cleaned with bleach and ethanol between

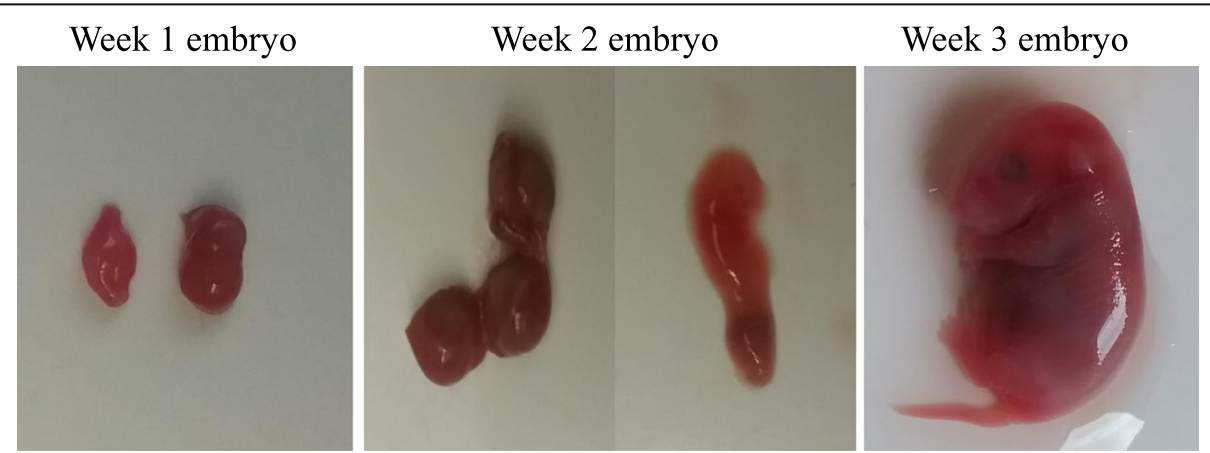

Fig. 1 Pictures of embryos in the three stages of development, categorization was based on size and developmental characteristics of each embryo. Week 1 embryos were very small with little to no distinguishing characteristics. Week 2 embryos were larger and an embryo could be removed from its location in the uterus, a distinctive eye-spot was also observed. Week 3 embryos were large with almost fully developed characteristics 
each type of tissue collection. If the embryo was early in development the whole embryo was used for DNA extraction or the embryo was cut in half to equal $25 \mathrm{mg}$. If the embryo was in a later developmental stage the heart of the embryo was removed and used in the extraction process. All embryo samples were screened for the presence of $B$. microti using the quantitative PCR protocols described in the following section.

\section{DNA extraction and PCRs}

For all embryos and embryonic tissues, a $25 \mathrm{mg}$ sample was collected as described in the previous section, DNA was extracted by hand using the Qiagen DNeasy Blood and Tissue kit following the manufacturer's protocol (Qiagen, Valencia, CA, USA), and DNA concentration was analyzed using a spectrophotometer (Denovix Inc, New Castle County, Delaware, USA).

For adult samples, a $3 \mathrm{~mm}$ ear punch biopsy was collected from each mouse and DNA was extracted using the QIAcube HT DNA extraction system (Qiagen). DNA concentration was measured for each sample using a spectrophotometer (Denovix Inc). Each ear punch biopsy sample collected from adults was then tested in duplicate for the presence of $B$. burgdorferi using a quantitative PCR (qPCR) specific for a unique $69 \mathrm{bp}$ segment of the $16 S$ rRNA gene: forward primer (5'-GGC GGC ACA CTT AAC ACG TTA G-3'), reverse primer (5'-GCT GTA AAC GAT GCA CAC TTG GT-3'), probe (6FAM-TTC GGT ACT AAC TTT TAG TTA AMGBNFQ) [14]. Samples were run on a 7500 real-time PCR system (Applied Biosystems ${ }^{\circ}$, ThermoFisher Scientific, Waltham, WA, USA) using TaqMan Fast Advanced chemistry (ThermoFisher Scientific, Waltham, WA) and cycling conditions consisted of: $95^{\circ} \mathrm{C}$ for $20 \mathrm{~s}$, followed by 40 cycles of $95{ }^{\circ} \mathrm{C}$ for $3 \mathrm{~s}$ and $60{ }^{\circ} \mathrm{C}$ for $30 \mathrm{~s}$. Because $B$. burgdorferi is an extracellular bacterium and primarily observed in tissues, we restricted our screening of $B$. burgdorferi to only adult ear punch biopsy samples.

For adult individuals, DNA from dried blood samples was extracted from FTA cards using the QIAcube HT DNA extraction system or by hand using the Qiagen DNeasy Blood and Tissue kit following the manufacturer's protocol (Qiagen). DNA concentration was analyzed using a spectrophotometer (Denovix Inc). Embryos, embryonic tissues, and adult blood samples, were screened in duplicate for the presence of $B$. microti using a qPCR designed specifically for detecting a 104 bp section of the $18 S$ rRNA gene of $B$. microti: forward primer (5'-AAC AGG CAT TCG CCT TGA AT-3'), reverse primer (5'-CCA ACT GCT CCT ATT AAC CAT TAC TCT-3'), probe (6FAM-CTA CAG CAT GGA ATA ATG A-MGBNFQ) [15]. Babesia microti is primarily an intracellular erythrocytic protozoan and therefore we analyzed embryos, embryonic tissues, and adult dried blood samples for the presence of B. microti. Because blood samples could not be obtained from embryos, a $25 \mathrm{mg}$ sample of heart tissue was also collected and analyzed from a subset of adult mice for direct comparison to embryos and embryonic tissues.

Average cycle threshold (CT) and quantity values were collected from each run and mean infection prevalence (number of infected individuals/total number of individuals) was calculated for each location. qPCR standards were constructed by separately cloning the aforementioned targeted regions of $B$. burgdorferi and B. microti into pUC57-Kan plasmids (GENEWIZ, Inc., South Plainfield, NJ, USA). A dilution series $\left(10^{6}-1\right.$ copy number dilutions) for each pathogen was developed by combining a single uninfected $I$. scapularis nymph (courtesy of the CDC) and a known amount of plasmid DNA followed by DNA extraction [14, 15]. Quantification and normalization of each sample were completed as previously described [14, 16, 17]; results are expressed as gene copies per picogram (pg) of total DNA.

Babesia microti positive samples, determined via qPCR, were then subjected to a standard PCR using a specific primer set to amplify $437 \mathrm{bp}$ of the $B$. microti $18 S$ rRNA gene (forward PIRO-A: 5'-AAT ACC CAA TCC TGA CAC AGG G-3' and reverse PIRO-B: 5'-TTA AAT ACG AAT GCC CCC AAC-3') [18]. Amplification was performed using Platinum Superfi $2 \times$ PCR Master Mix (Invitrogen, ThermoFisher Scientific, Waltham, WA, USA) under the following conditions: $98{ }^{\circ} \mathrm{C}$ for $30 \mathrm{~s}$, followed by 40 cycles of $98^{\circ} \mathrm{C}$ for $10 \mathrm{~s}, 60^{\circ} \mathrm{C}$ for $10 \mathrm{~s}$, and $72{ }^{\circ} \mathrm{C}$ for $1 \mathrm{~min}$, with a final elongation step of $72{ }^{\circ} \mathrm{C}$ for 5 min. PCR products were subjected to gel electrophoresis on a $1 \%$ agarose gel stained with ethidium bromide. Amplicons that produced bands of the correct size $(\sim 450$ bp) were submitted for Sanger sequencing (Eurofins, Louisville, KY, USA) in both the forward and reverse directions. Consensus sequences were constructed and aligned with other orthologous $B$. microti sequences deposited in the GenBank database and previously described as human-infecting Clade 1 and nonhuman-associated Clade 2 and Clade 3 pathogens (AY144696, AY144701, AY144690; respectively) [19]. Alignments were completed by hand using BioEdit Sequencing Alignment Editor [20] and using the online Multiple Sequence Comparison by Log-Expectation Alignment (MUSCLE) program. Sequence diversity and a pairwise distance matrix were constructed using the maximum composite likelihood model in MEGA version 7.0 software [21].

\section{Statistical analyses}

Infection prevalence was calculated for sex of adults, embryonic tissue type, and embryonic stage of development. Significant differences between the proportion of individuals infected and not-infected with $B$. burgdorferi 
were evaluated using a Fisher's exact test. A Student's ttest was used to compare the number of nymphs collected from April mice, individuals infected with B. burgdorferi and/or B. microti in April mice between males and females, between CT and BI, and to compare female infection to embryo infection overall and between trapping sessions. A nonparametric Kruskal-Wallis test was performed to assess differences in B. microti infection in the stages of embryonic development and the average number of embryos in each developmental stage. A pairwise Wilcoxon test was used to determine the variation between each stage of development. Finally, an analysis of variance (ANOVA) was completed to determine differences in parasitemia between the three stages of embryonic development. Geometric means of duplicate samples were used in all calculations.

\section{Results}

All mice collected in April and only pregnant females $(n=6)$ and their embryos $(n=26)$ collected in July were necropsied and analyzed for the presence of $B$. burgdorferi and $B$. microti using qPCR. In the April sampling session, a total of 63 P. leucopus mice were collected from the Connecticut (CT) locations and 40 from the Block Island (BI) locations (Table 1). Of these, the combined proportion of mice with attached $I$. scapularis nymphs was $57.89 \%(n=32$ CT mice, $n=26$ BI mice). Overall, $12.62 \%(\mathrm{CT}=9.53 \%$; $\mathrm{BI}=17.5 \%)$ of mice were infected with $B$. burgdorferi and $100 \%$ with $B$. microti. The average $B$. burgdorferi log mean copy number per pg total DNA (MCN) did not vary significantly between CT and BI (Table 1) or between infected males $\left(n_{\mathrm{CT}}=4 ; n_{\mathrm{BI}}=5\right)$ and females $\left(n_{\mathrm{CT}}=2 ; n_{\mathrm{BI}}=2\right)$. No significant differences in $B$. microti $\mathrm{MCN}$ were observed between CT and BI (Table 1) or between infected males $(n=$ 55 ; MCN \pm standard error $=5.25 \pm 0.09)$ and females $(n=$ $48 ; \mathrm{MCN}=5.20 \pm 0.10)$.

Table 1 Log mean copy number per pg total DNA (MCN) calculations and standard errors (SE) for Borrelia burgdorferi and Babesia microti from Connecticut locations: Lake Gaillard (LG) and Old Lyme (OL) and Block Island locations: North Island (NI) and Rodman's Hollow (RH) for all Peromyscus leucopus collected in April

\begin{tabular}{cllllll}
\hline & & \multicolumn{2}{l}{ B. burgdorferi } & & \multicolumn{2}{c}{ B. microti } \\
& $n$ & MCN & SE & & MCN & SE \\
\hline Connecticut & 63 & 4.29 & 0.25 & & 5.27 & 0.10 \\
LG & 27 & 3.95 & 0.29 & & 5.43 & 0.18 \\
OL & 36 & 4.46 & 0.34 & 5.14 & 0.10 \\
Block Island & 40 & 4.35 & 0.20 & 5.17 & 0.10 \\
NI & 15 & 3.75 & 0.09 & 5.01 & 0.18 \\
RH & 25 & 4.59 & 0.17 & 5.27 & 0.11 \\
\hline
\end{tabular}

Of the total small mammals sampled in 2016, $20 P$. leucopus females were pregnant $\left(n_{\mathrm{CT}}=12 ; n_{\mathrm{BI}}=8\right)$, including three and five mice collected on BI in April and July, respectively. All 12 pregnant females from CT were collected in April. One pregnant meadow vole (Microtus pennsylvanicus) was collected on BI in July and was included in some of the analyses. Four pregnant mice and the vole tested positive for B. burgdorferi (25.0\%). All blood samples collected from adult pregnant females tested positive for the presence of $B$. microti via $\mathrm{qPCR}$ (100\%) and no significant differences were observed between $\mathrm{CT}$ and BI females. The number of embryos per female (mouse only) ranged from 2-6 with an average of 4.5 embryos per female (Table 2; Additional file 1: Table S1). A significant difference among the average number of embryos was observed (Kruskal-Wallis $\chi^{2}=8.13$, $d f=2, P=0.0172)$. The average number of embryos in Week $1(n=3.4)$ was not significantly different from the number of embryos in Week $2(n=4.8$; Wilcoxon test $P=$ 0.0660 ), however there were significantly more Week 3 embryos compared to Week 1 ( $n=5.1$; Wilcoxon test $P=$ 0.0360 ), but not compared to Week 2 (Wilcoxon test $P=0.4340 ;$ Fig. 2a). There were no significant differences observed in the average number of embryos between trapping sessions.

A total of 89 mouse embryos were collected and tested for the presence of $B$. microti. Week 1 embryos showed the highest infection prevalence (91.67\%), whereas Week 3 embryo infection was lowest (56.10\%); the average infection prevalence among all embryos was $74.16 \%$ (Table 2). The average $B$. microti MCN was significantly different among the three stages of embryonic development (Kruskal-Wallis $\chi^{2}=16.04, d f=2, P=0.0003$ ). Embryos from Week $1(\mathrm{MCN}=2.55 \pm 0.17)$ and Week $2(\mathrm{MCN}=$ $2.49 \pm 0.18$ ) displayed significantly higher parasitemia than embryos from the Week 3 stage of development $(\mathrm{MCN}=1.64 \pm 0.11$; Wilcoxon test $P=0.0003$ and $P$ $=0.0022$, respectively; Fig. $2 \mathrm{~b}$ ), but not between each other (Wilcoxon test $P=0.8948$ ). Other reproductive tissue types (uterus, placenta, embryonic sac) also tested positive for B. microti (Additional file 2: Table S2), but due to the differences in embryo developmental stage not all tissue types could be collected at each of the three stages.

Females displayed significantly higher $B$. microti parasitemia $(n=21 ; \mathrm{MCN}=4.40 \pm 0.21)$ than their embryos $(n=71 ; \mathrm{MCN}=2.29 \pm 0.10 ; P<0.0001 ;$ Fig. 3$)$. April females $(n=15 ; \mathrm{MCN}=4.67 \pm 0.24)$ showed significantly higher parasitemia than pregnant females from July $(n=$ 6 including the $M$. pennsylvanicus female; $\mathrm{MCN}=3.73$ $\pm 0.35 ; P=0.0502)$. Conversely, July embryos $(n=20$; $\mathrm{MCN}=2.66 \pm 0.22$ ) exhibited a significantly higher MCN than embryos from April $(n=51 ; \mathrm{MCN}=2.15 \pm$ $0.10 ; P=0.0477)$. To assess differences in $\mathrm{MCN}$ among 
Table 2 The mean number of embryos at each embryonic stage of development, the total number of embryos in each stage, the number of those embryos infected with Babesia microti, and the infection prevalence of mouse embryos for each stage of embryonic development is presented

\begin{tabular}{llllll}
\hline & Mean no. embryos & No. embryos & No. infected & \% infected & MCN \\
\hline Week 1 & 3.4 & 24 & 22 & 91.67 & 2.55 \\
Week 2 & 4.8 & 24 & 21 & 87.50 & 2.50 \\
Week 3 & 5.1 & 41 & 23 & 56.10 & 1.64 \\
Total & 4.5 & 89 & 66 & 74.16 & 2.22 \\
\hline
\end{tabular}

See Additional file 1: Table S1 for detailed information of each individual female

different sample types, we also compared heart tissue $(n=$ 11$, MCN $4.61 \pm 0.24)$ and blood samples $(n=11, \mathrm{MCN}=$ $5.00 \pm 0.26)$ collected from a subset of adult mice and found that they did not differ significantly $(P=0.2757)$.

Sequences in the forward and reverse directions of the $18 S$ rRNA gene of $B$. microti were obtained for six individuals including each embryo, adult female uterine arteries and veins, uterus, placenta, and embryonic sac (total sequences $=76$; Additional file 3: Figure S1). Consensus sequences were constructed and BLAST analysis (NCBI) confirmed all sequences to be strains of $B$. microti (XR_002459986 or AF028343). Most sampled sequences aligned nearly identically to the reference sequence for Clade 1 (AY144696), except for one sample of adult female arteries (2033-Arteries). The overall pairwise mean distance and sequence diversity was 0.005 for all embryonic samples (0.001 when 2033-Arteries was excluded) including the reference sequence for Clade 1 (AY144696) and 0.014 (0.011 when 2033-Arteries was excluded) when reference sequences from Clade 2 (AY144701) and Clade 3 (AY144690) were added. Unique $B$. microti sequences generated from this study have been deposited in GenBank (accession nos. MH221125, MH221126).

\section{Discussion}

Our study demonstrates for the first time that transplacental transmission of $B$. microti occurs in wild, naturally-infected populations of $P$. leucopus and $M$. pennsylvanicus in Connecticut and on Block Island, RI, USA, with $74 \%$ transmission efficiency from mother to fetuses. Although studies have previously reported transplacental transmission of Babesia canis canis in canines [22, 23], B. microti in BALB/c laboratory mice [24], and humans $[25,26]$ only one other study has reported vertical transmission of $B$. microti occurring in naturally infected rodent populations [27]. Tolkacz and colleagues [27] reported vertical transmission of B. microti in two

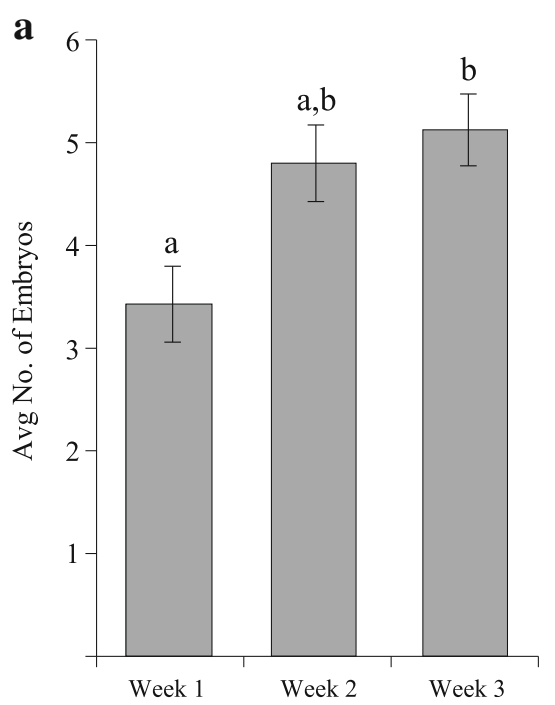

Embryonic Stage of Development

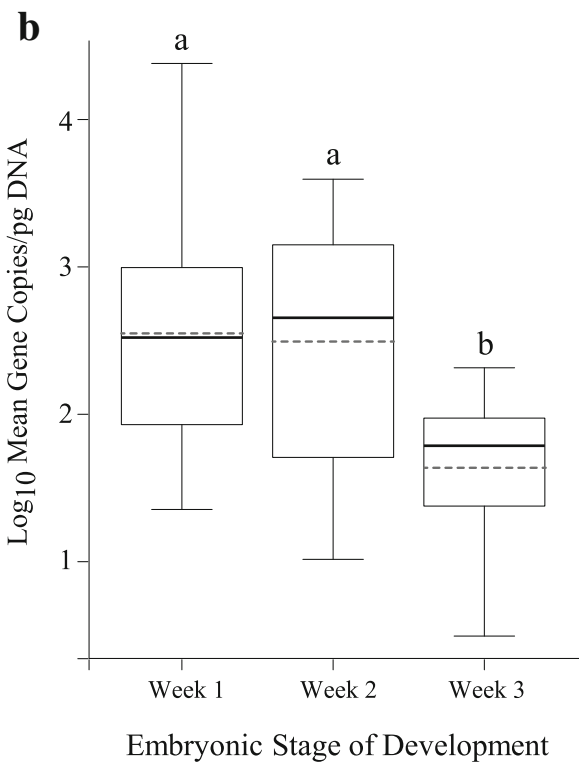

Embryonic Stage of Development

Fig. 2 The average number of embryos in pregnant Peromyscus leucopus (a) and a box plot of the log mean copy number/pg DNA (MCN) of Babesia microti in embryos (b) in different stage of embryo development. Significantly fewer embryos were collected in Week 1 than in Week $3(P=0.0360)$. Parasitemia was significantly lower in Week 3 embryos compared to Week 1 and $2(P<0.0003$ and $P=0.0022$, respectively). Solid lines denote median values while dashed lines denote the means, different letters denote significant differences 


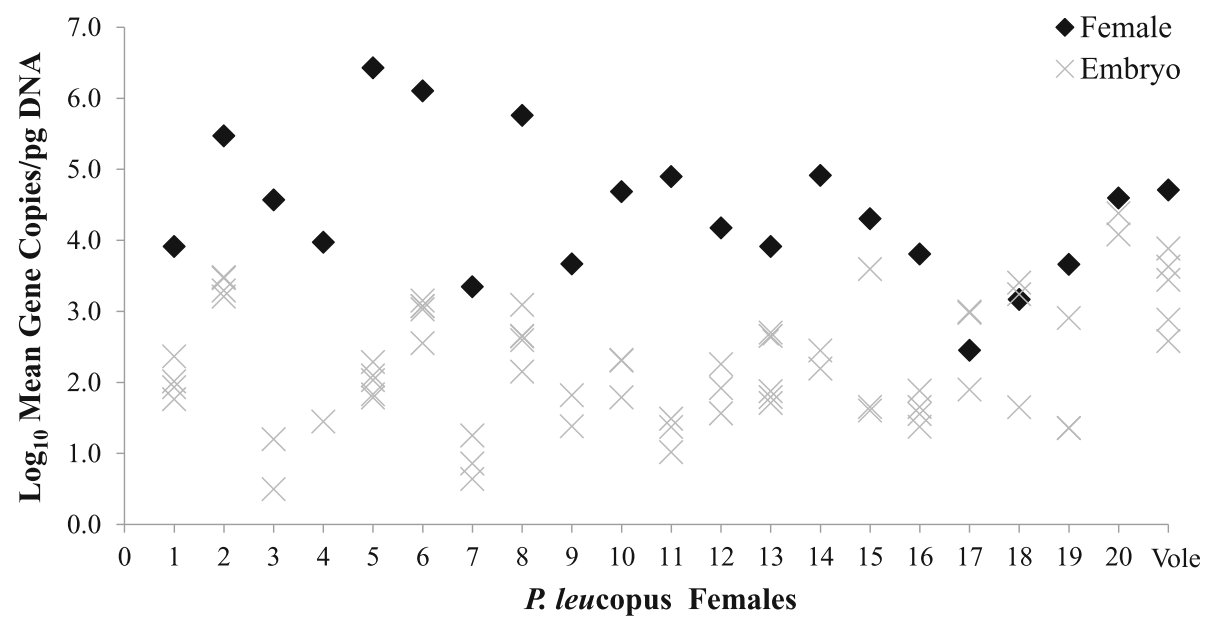

Fig. 3 Babesia microti log mean copy number per pg of total DNA (MCN) comparing females to each of her infected embryos. Positions 1-20 are Peromyscus leucopus pregnant females; 1-16 were samples collected in April; 17-20 were collected in July, and the last position is of the single Microtus pennsylvanicus female (Vole) collected in July. Females (black diamonds) overall exhibited significantly higher parasitemia (MCN \pm standard error, $4.405 \pm 0.21$ ) than their offspring (gray $X ; 2.291 \pm 0.10 ; P<0.0001$ )

species of vole (Microtus arvalis and M. oeconomus) in Poland, finding $81 \%$ infection occurring in embryos and $90 \%$ in pups. Here, we report transplacental transmission in $P$. leucopus and a third species of vole, $M$. pennsylvanicus.

All individuals were infected with B. microti in April, in contrast to only $12.6 \%$ of individuals infected with $B$. burgdorferi. These mice could have been infected by nymphal $I$. scapularis in the spring or could have survived and maintained the infection through the winter months (chronic infection). Because nymphal I. scapularis were found on $50.8 \%$ of mice collected in CT and $65.0 \%$ of mice collected on BI, it is possible these mice all became infected by questing nymphs once they emerged from their winter burrows. However, because a higher proportion of nymphal I. scapularis are typically infected with B. burgdorferi $(22.37 \%$ average infection prevalence) than B. microti (9.53\% average infection prevalence) in the New England area (comparing 10 studies and 9335 nymphal $I$. scapularis samples) [6], the higher $B$. microti infection prevalence in mice requires an alternative explanation. A combination of vertical transmission and chronic infection with $B$. microti through the winter months would amplify B. microti even before most ticks emerged from diapause, typically in mid to late May [6], providing a transmission advantage compared to $B$. burgdorferi. The duration of $B$. microti infection in naturally infected (via tick vector) $P$. leucopus is unclear; however, chronic infection has been shown to persist in laboratory $P$. leucopus for seven months and possibly longer [9, 10, 28, 29]. Chronic infection of $B$. microt $i$ was also observed for approximately five months in naturally infected voles from Russia [30]. In these ways mice infected over the transmission season
(April-July) could remain infected until the following spring, when transplacental transmission could further increase early-season transmission. Resistance to reinfection is unknown in Peromyscus; consequently, mice could either become re-infected or B. microti could become reactivated every transmission season resulting in chronic infection and an increase of the pathogen in the population via vertical transmission. Reactivation of certain pathogens has been shown to occur during stressful life events (i.e. migration in birds) [31, 32]. Seasonal physiological stress (i.e. cold temperatures during winter months) may allow for reactivation of B. microti and provide an additional explanation for prolonged infection in wild $P$. leucopus.

The relative timing of insemination and infection in the mother may be important determinants of the survivorship and infection outcome of fetuses [24, 33]. The breeding season of $P$. leucopus in our study region starts around March, while nymphal tick activity typically starts in April or May, although both events are highly dependent on seasonal variation in temperature [34]. Furthermore, peak B. microti parasitemia in P. leucopus occurs 14 days after infection via tick bite [35]. Given the differences in mouse and tick life cycles, females captured in April were more likely inseminated before B. microti infection via ticks. The lower average number of Week 1 compared to Week 3 embryos may be explained by the higher likelihood of reabsorption of some or all embryos when the female is inseminated simultaneously or before infection. Reabsorption of embryos was suggested in a study using $\mathrm{BALB} / \mathrm{c}$ laboratory mice which found that females inseminated in the acute phase of $B$. microti infection (0-12 days) did not produce any offspring [24]. Reabsorption of fetuses when mice are infected early in 
the gestation period has also been observed in other pathogens, such as Neospora caninum in BALB/c laboratory mice [33]. A significantly higher number of Week 3 embryos with significantly lower parasitemia compared to embryos in earlier stages of development (Week 1 and 2) was observed. This may also indicate that females became infected with $B$. microti after insemination or during later stages of gestation and the pathogen had not fully disseminated to all embryos when the female was euthanized. Experimental manipulation of the timing of infection and insemination is required to fully characterize the affect $B$. microti may have on developing fetuses and pathogen persistence.

Females exhibited significantly higher parasitemia compared to their offspring. Although the different tissues investigated could partially account for this difference, we found no significant differences in $\mathrm{MCN}$ in a subset of samples of adult heart tissue and blood. Decreased parasitemia in embryos may thus be due to limited placenta permeability. Although the placenta is known to function as a barrier to potentially harmful microbes and pathogens [36], multiple parasites and pathogens have developed ways of evading the placental barrier to infect a fetus, including another apicomplexan, Plasmodium spp. [37], as well as Toxoplasma gondii [38], Trypanosoma spp. [39], and several nematodes [40, 41]. Similar to Plasmodium spp., B. microti sporozoites invade host red blood cells and are able to breach the placental barrier to infect a female's offspring [42]; exactly how these pathogens are able to diffuse through the placenta is unknown.

Tolkacz and colleagues [27] found different genotypes of B. microti in female voles and their offspring, although the mechanisms for these differences were not explained. This was not the case in our study, with sequences from $P$. leucopus and M. pennsylvanicus revealing high similarity between females and fetuses and overall. Low genome-wide sequence diversity was also observed in other studies [43, 44]. Some studies suggest that $B$. microti represents a rich species complex consisting of three distinct clades in the United States using the $18 S$ rRNA gene; however genetic diversity within each clade is relatively invariant [19]. Strains in Clade 1 are found associated with human-biting Ixodes species, locations known to be endemic for human babesiosis, and exhibit the least amount of genetic diversity. Whereas strains in Clade 2 were isolated from carnivores and those in Clade 3 were found to infect rodents; neither Clade 2 nor 3 have been found to infect humans. Sequences from this study most closely aligned with the reference sequence from Clade 1 and these sequences showed a low sequence diversity of 0.001 . One of our sequences (2033-Arteries) exhibited higher diversity than predicted by previous studies; this might have occurred due to multiple infections or interference from other pathogens during Sanger sequencing (resulting in a noisy chromatograph) and most likely does not represent a unique $B$. microti species.

Our field-based results indicate that transplacental transmission of $B$. microti is a potentially important pathway for infection in wild rodent species, $P$. leucopus and $M$. pennsylvanicus, which may partially explain B. microti emergence and geographic expansion. In endemic areas, transplacental transmission may enhance early season amplification of B. microti, contributing to higher infection prevalences in both hosts and vectors. Additional enhancement mechanisms have been described, including increased transmission of $B$. microti to ticks feeding on hosts coinfected with $B$. burgdorferi based in field and laboratory studies $[6,11,35]$ and amplification driven by tick aggregation, as shown in an empirically-informed model [45]. Transplacental transmission in natural populations may also facilitate $B$. microti maintenance and spread in small rodent populations in areas with limited I. scapularis occurrence. For instance, in areas of Alaska, California, Colorado, Florida, Maine, and Montana that lack I. scapularis, small rodent populations (voles, shrews, cotton rats, other Peromyscus spp.) were infected with both human-infecting and nonhuman-associated strains of B. microti [46-50]. Some evidence suggests that nidicolous ticks (e.g. I. angustus, I. muris, I. spinipalpis) or other exophilic ticks (I. pacificus) may contribute moderate enzootic persistence in certain areas [48] in a 'cryptic cycle', but vertical transmission may also play a role. Irrespective of the maintenance mechanism in the enzootic cycle, transmission to humans and emergence would only occur when I. scapularis (a 'bridge' vector to humans) invades a region where $B$. microti had been enzootically maintained, as has been shown for $B$. burgdorferi $[49,51]$.

To confirm the relevance of transplacental and vertical transmission in B. microti, studies in a laboratory setting are required to specifically quantify the relative efficiencies of $B$. microti transmission routes, including tick-to-host transmission, vertical transmission in relation to insemination and infection timing, chronic infection, and xenodiagnoses and transmission efficiency of infected offspring. More extensive field studies quantifying the role of vertical transmission and chronic infection of $B$. microti should then be conducted to assess how these transmission pathways influence this pathogen's persistence and transmission, in comparison to B. burgdorferi. As winter temperatures in these areas continue to increase each year [52], overwinter survival of mice may increase [53, 54], further enhancing the early season advantage of $B$. microti through chronic infection and vertical transmission. 


\section{Conclusions}

We demonstrate that transplacental transmission of $B$. microti occurs with high efficiency in wild rodent populations in New England. This non-vector mediated transmission mode may result in significant pathogen amplification, in particular if combined with chronic infection in the host and increased overwintering survival in warming climates.

\section{Additional files}

Additional file 1: Table S1. Information for each pregnant female and infection status of her embryos collected in April and July, 2016. Site: LG, Lake Gaillard; OL, Old Lyme; RH, Rodman's Hollow; NI, North Island. Age of embryos: W1, Week 1; W2, Week 2; W3, Week 3. (DOCX 19 kb)

Additional file 2: Table S2. Babesia microti infection prevalence in reproductive tissues (ES, embryonic sac). (DOCX $14 \mathrm{~kb}$ )

Additional file 3: Figure S1. Babesia microti sequence alignment from embryos and tissues of the 18S rRNA gene for six females (labeled by a four digit identification number) including three reference sequences representing the three Babesia clades (Clade-1, AY144696; Clade-2, AY144701; Clade-3, AY144690). (DOCX 136 kb)

\section{Abbreviations}

Bl: Block Island, Rhode Island; CT: Connecticut; LG: Lake Gaillard; MCN: Iog mean copy number/pg of DNA; NI: North Island; OL: Old Lyme; qPCR: Quantitative polymerase chain reaction; $\mathrm{RH}$ : Rodman's Hollow

\section{Acknowledgments}

The authors would like to thank Sarah Dube, Elsbeth Kane, Christina Olbrantz and Evelyn Rynkiewicz for assistance collecting mice in the field and Maria Fernandez for statistical assistance.

\section{Funding}

This research was made possible by a grant from the National Institutes of Health, Ecology and Evolution of Infectious Disease Program to MDW (R01 GM105246).

\section{Availability of data and materials}

The data supporting the conclusions of this article are included within the article. Unique B. microti sequences have been deposited in the GenBank database under the accession numbers MH221125 and MH221126. The raw data are available from the corresponding author upon reasonable request.

\section{Authors' contributions}

DMT and MDW designed the study. DMT collected the data from the field and analyzed each individual in the laboratory. DMT performed all statistical analyses. DMT and MDW wrote the manuscript. Both authors read and approved the final manuscript.

\section{Ethics approval and consent to participate}

All animal procedures were in accordance with guidelines approved by the Columbia University Institutional Animal Care and Use Committee (IACUC no. AC-AAAL3656)

\section{Competing interests}

The authors declare that they have no competing interests.

\section{Publisher's Note}

Springer Nature remains neutral with regard to jurisdictional claims in published maps and institutional affiliations.
Received: 1 February 2018 Accepted: 26 April 2018

Published online: 04 May 2018

\section{References}

1. Vannier EG, Diuk-Wasser MA, Mamoun CB, Krause PJ. Babesiosis. Infect Dis Clin North Am. 2015:29:357-70.

2. Spielman A. The emergence of Lyme disease and human babesiosis in a changing environment. Ann NY Acad Sci. 1994;740:146-56.

3. Piesman J, Mather TN, Telford SR III, Spielman A. Concurrent Borrelia burgdorferi and Babesia microti infection in nymphal Ixodes dammini. J Clin Microbiol. 1986;24:446-7.

4. Piesman J, Mather TN, Dammin GJ, Telford SR III, Lastavica CC, Spielman A. Seasonal variation of transmission risk of Lyme disease and human babesiosis. Am J Epidemiol. 1987;126:1187-9.

5. Diuk-Wasser MA, Liu Y, Steeves T, Folsom-O'Keefe C, Dardick KR, Lepore T, et al. Monitoring human babesiosis emergence through vector surveillance, New England, USA. Emerg Infect Dis. 2014;20:225-31.

6. Diuk-Wasser MA, Vannier E, Krause PJ. Coinfection by lxodes tick-borne pathogens: Ecological, epidemiological, and clinical consequences. Trends Parasitol. 2016:32:30-42.

7. Walter KS, Pepin KM, Webb CT, Gaff HD, Krause PJ, Pitzer VE, Diuk-Wasser MA. Invasion of two tick-borne diseases across New England: harnessing human surveillance data to capture underlying ecological invasion processes. Proc Biol Sci. 2016:283:S301-27.

8. Davis S, Bent SJ. Loop analysis for pathogens: Niche partitioning in the transmission graph for pathogens of the North American tick /xodes scapularis. J Theor Biol. 2011;269:96-103.

9. Mather TN, Telford SR III, Moore SI, Spielman A. Borrelia burgdorferi and Babesia microti: Efficiency of transmission from reservoirs to vector ticks (Ixodes dammini). Exp Parasitol. 1990;70:55-61.

10. Telford SR III, Spielman A. Reservoir competence of white-footed mice for Babesia microti. J Med Entomol. 1993;30:223-7.

11. Hersh MH, Ostfeld RS, McHenry DJ, Tibbetts M, Brunner JL, Killilea ME, et al. Co-infection of blacklegged ticks with Babesia microti and Borrelia burgdorferi is higher than expected and acquired from small mammal hosts. PLoS One. 2014;9:9-13.

12. Gerber MA, Zalneraitis EL. Childhood neurologic disorders and Lyme disease during pregnancy. Pediatr Neurol. 1994;11:41-3.

13. Shapiro ED, Gerber MA. Lyme disease. In: Remington JS, Klein JO, Wilson CB, Baker CJ, editors. Infectious diseases of the fetus and newborn infant. 6th ed. Philadelphia: Elsevier Saunders; 2006. p. 485-97.

14. Barbour AG, Bunikis J, Travinsky B, Hoen AG, Diuk-Wasser MA, Fish D, Tsao الر Niche partitioning of Borrelia burgdorferi and Borrelia miyamotoi in the same tick vector and mammalian reservoir species. Am J Trop Med Hyg. 2009;81: 1120-31.

15. Rollend L, Bent SJ, Krause PJ, Usmani-Brown S, Steeves TK, States SL, et al. Quantitative PCR for detection of Babesia microti in Ixodes scapularis ticks and in human blood. Vector-Borne Zoonot. 2013;13:784-90.

16. Baum E, Hue F, Barbour AG. Experimental infections of the reservoir species Peromyscus leucopus with diverse strains of Borrelia burgdorferi, a Lyme disease agent. MBio. 2012;3:e00434-12.

17. Barbour AG, Bunikis J, Fish D, Hanincova K. Association between body size and reservoir competence of mammals bearing Borrelia burgdorferi at an endemic site in the northeastern United States. Parasit Vectors. 2015;8:299.

18. Armstrong PM, Katavolos P, Caporale DA, Smith RP, Spielman A, Telford SA. Diversity of Babesia infecting deer ticks (Ixodes dammini). Am J Trop Med Hyg. 1998;58:739-42

19. Goethert HK, Telford SR III. What is Babesia microti? Parasitol. 2003;127:301-9

20. Hall TA. BioEdit: a user-friendly biological sequence alignment editor and analysis program for Windows 95/98/NT. Nucl Acids Symp Ser. 1999;41:95-8.

21. Kumar S, Stecher G, Tamura K. MEGA7: Molecular evolutionary genetics analysis version 7.0 for bigger datasets. Mol Bio Evol. 2016;33:1870-4.

22. Mierzejewska EJ, Welc-Faleciak R, Bednarska M, Rodo A, Bajer A. The first evidence for the vertical transmission of Babesia canis in a litter of Central Asian Shepherd dogs. Ann Agric Environ Med. 2014;21:500-3.

23. Adaszek L, Obara-Galek J, Piech T, Winiarczyk M, Kalinowski M, Winiarczyk S. Possible vertical transmission of Babesia canis canis from a bitch to her puppies: a case report. Vet Med-Czech. 2016;61:263-6.

24. Bednarska M, Bajer A, Drozdowska A, Mierzejewska EJ, Tolkacz K, WelcFaleciak R. Vertical transmission of Babesia microti in BALB/c mice: Preliminary report. PLoS One. 2015;10:1-13. 
25. New DL, Quinn JB, Qureshi MZ, Sigler SJ. Vertically transmitted babesiosis. J Pediatr. 1997;131:163-4.

26. Joseph JT, Purtill K, Wong SJ, Munoz J, Teal A, Madison-Antenucci S, et al. Vertical transmission of Babesia microti, United States. Emerg Infect Dis. 2012;18:1318-21.

27. Tolkacz K, Bednarska M, Alsarraf M, Dwuznik D, Grzybek M, Welc-Faleciak R, et al. Prevalence, genetic identity and vertical transmission of Babesia microti in three naturally infected species of vole, Microtus spp. (Cricetidae) Parasit Vectors. 2017;10:66

28. Spielman A, Etkind P, Piesman J, Ruebush TK II, Juranek DD, Jacobs MS. Reservoir hosts of human babesiosis on Nantucket Island. Am J Trop Med Hyg. 1981;30:560-5.

29. Piesman J. Intensity and duration of Borrelia burgdorferi and Babesia microti infectivity in rodent hosts. Int J Parasitol. 1988;18:687-9.

30. Rar V, Yakimenko V, Makenov M, Tikunov A, Epikhina T, Tancev A. High prevalence of Babesia microti 'Munich' type in small mammals from an Ixodes persulcatus/lxodes trianguliceps sympatric area in the Omsk region, Russia. Parasitol Res. 2016;115:3619-29.

31. Gylfe A, Bergstrom S, Lundstrom J, Olsen B. Reactivation of Borrelia infection in birds. Nature. 2000;403:724-5.

32. Gern L, Humair PF. Ecology of Borrelia burgdorferi sensu lato in Europe. In: Gray J, Kahl O, Lane RS, Stanek G, editors. Lyme Borreliosis: Biology, epidemiology, and control. Wallinford, UK: CAB International Publishing; 2002. p. 149-174.

33. Quinn HE, Ellis JT, Smith NC. Neospora caninum: a cause of immunemediated failure of pregnancy? Trends Parasitol. 2002;18:391-4.

34. Levi T, Keesing F, Oggenfuss K, Ostfeld RS. Accelerated phenology of blacklegged ticks under climate warming. Phil Trans R Soc B. 2015;370: 20130556.

35. Dunn JM, Krause PJ, Davis S, Vannier EG, Fitzpatrick MC, Rollend L, et al. Borrelia burgdorferi promotes the establishment of Babesia microti in the Northeastern United States. PLoS One. 2014;9:e115494.

36. Wright C, Sibley CP. Placental transfer in health and disease. In: Kay HH, Nelson DM, Wang Y, editors. The placenta: From development to disease. West Sussex, UK: John Wiley and Sons; 2011. p. 66-74.

37. Poovassery J, Moore JM. Murine malaria infection induces fetal loss associated with accumulation of Plasmodium chabaudi AS-infected erythrocytes in the placenta. Infect Immun. 2006;74:2839-48.

38. Chaudhry SA, Gad N, Koren G. Toxoplasmosis and pregnancy. Can Fam Physician. 2014;60:334-6.

39. Carlier Y, Truyens C, Deloron P, Peyron F. Congenital parasitic infections: a review. Acta Trop. 2012;121:55-70

40. da Costa-Macedo LM, Rey L. Ascaris lumbricoides in neonate: evidence of congenital transmission of intestinal nematodes. Rev Inst Med Trop Sao Paulo. 1990;32:351-4.

41. Shoop WL, Michael BF, Eary CH, Haines HW. Transmammary transmission of Strongyloides stercoralis in dogs. J Parasitol. 2002;88:536-9.

42. Malhotra I, Mungai P, Muchiri E, Kwiek JJ, Meshnick SR, King CL. Umbilical cord-blood infections with Plasmodium falciparum malaria are acquired antenatally in Kenya. J Infect Dis. 2006:194:176-83.

43. Goethert HK, Telford SR III. Not "out of Nantucket": Babesia microti in southern New England comprises at least two major populations. Parasit Vectors. 2014;7:546.

44. Capri G, Walter KS, Mamoun CB, Krause PJ, Kitchen A, Lepore TJ, et al. Babesia microti from humans and ticks hold a genomic signature of strong population structure in the United States. BMC Genomics. 2016;17:888.

45. Randolph SE. Quantifying parameters in the transmission of Babesia microti by the tick Ixodes trianguliceps amongst voles (Clethrionomys glareolus). Parasitol. 1995;110:287-95.

46. Fay FG, Rausch RL. Parasitic organisms in the blood of arvicoline rodents in Alaska. J Parasitol. 1969:55:1258-65.

47. Burkot TR, Schneider BS, Pieniazek NJ, Happ CM, Rutherford JS, Slemenda SB. Babesia microti and Borrelia bissettii transmission by Ixodes spinipalpis ticks among pine voles Microtus ochrogaster in Colorado. Parasitology. 2000; 121:595-9.

48. Goethert HK, Lubelcyzk C, LaCombe E, Holman M, Rand P, Smith RP, Telford SR III. Enzootic Babesia microti in Maine. J Parasitol. 2003;89:1069-71.

49. Hamer SA, Hickling GJ, Sidge JL, Rosen ME, Walker ED, Tsao Jl. Diverse Borrelia burgdorferi strains in a bird-tick cryptic cycle. Appl Environ Microbiol. 2011;77:1999-2007.

50. Clark K, Savick K, Butler J. Babesia microti in rodents and raccoons from northeast Florida. J Parasitol. 2012;98:1117-21.
51. Tsao Jl. Reviewing molecular adaptations of Lyme borreliosis spirochetes in the context of reproductive fitness in natural transmission cycles. Vet Res. 2009;40:36.

52. Hughes L. Biological consequences of global warming: is the signal already apparent? TREE. 2000;15:56-61.

53. Merritt JF, Zegers DA. Maximizing survivorship in cold: thermogenic profiles of non-hibernating mammals. Acta Theol. 2002;47:221-34.

54. Roy-Defresne E, Logan T, Simon JA, Chmura GL, Millien V. Poleward expansion of the white-footed mouse (Peromyscus leucopus) under climate change: implications for the spread of Lyme disease. Plos One. 2013;8: e80724.

\section{Ready to submit your research? Choose BMC and benefit from}

- fast, convenient online submission

- thorough peer review by experienced researchers in your field

- rapid publication on acceptance

- support for research data, including large and complex data types

- gold Open Access which fosters wider collaboration and increased citations

- maximum visibility for your research: over $100 \mathrm{M}$ website views per year

At BMC, research is always in progress.

Learn more biomedcentral.com/submissions 